\title{
Position Control of a Three Degree of Freedom Gyroscope using Optimal Control
}

\author{
Mustefa Jibril ${ }^{1}$, Messay Tadese ${ }^{2}$, Nuriye Hassen ${ }^{3}$ \\ ${ }^{1}$ Msc, School of Electrical \& Computer Engineering, Dire Dawa Institute of Technology, Dire Dawa, \\ Ethiopia \\ ${ }^{2}$ Msc, School of Electrical \& Computer Engineering, Dire Dawa Institute of Technology, Dire Dawa, \\ Ethiopia \\ ${ }^{3}$ Msc, School of Electrical \& Computer Engineering, Dire Dawa Institute of Technology, Dire Dawa, \\ Ethiopia \\ mustefa.jibril@ddu.edu.et
}

\begin{abstract}
In this paper, a 3 DOF gyrscope position control have been designed and controlled using optimal control theory. An input torque has been given to the first axis and the angular position of the second axis have been analyzed while the third axis are kept free from rotation. The system mathematical model is controllable and observable. Linear Quadratic Integral (LQI) and Linear Quadratic State Feedback Regulator (LQRY) controllers have been used to improve the performance of the system. Comparison of the system with the proposed controllers for tracking a desired step and random angular position have been done using Matlab/Simulink Toolbox and a promising results has been analyzed.
\end{abstract}

Keywords: Gyrscope, Linear Quadratic Integral, Linear Quadratic State Feedback Regulator

\section{Introduction}

A gyroscope is a system used for measuring or accordance angular position and angular velocity. It is a spinning wheel in which the axis of rotation (spin axis) is free to assume any tendency by itself. When rotating, the tendency of this axis is unaffected by inclining or rotation of the mounting, according to the conservation of angular momentum. Gyroscopes based on other operating precept also exist, such as the microchip-packaged MEMS gyroscopes found in electronic devices and the extremely sensitive quantum gyroscope. A gyroscope is a wheel mounted in two or three gimbals, which are pivoted supports that allow the rotation of the wheel roughly a single axis. The axle of the spinning wheel defines the spin axis. The rotor is constrained to spin closely an axis, which is always perpendicular to the axis of the inner gimbal. So the rotor possesses three degree of rotational freedom and its axis possesses two. The wheel responds to a torque applied to the input axis by a response torque to the output axis.

\section{Mathematical Modeling of the Gyrscope}

The gyrscope system is shown in Figure 1 below. 


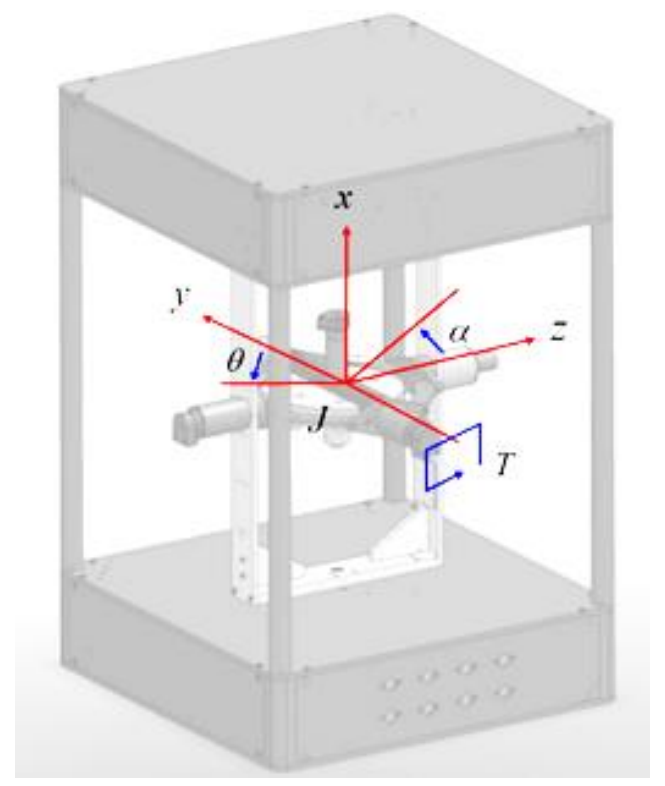

Figure 1 Gyrscope system

The equations of motion representing the angular rate of the $\mathrm{Z}$ axis $\alpha$ and the $\mathrm{y}$ axis $\theta$ are

$$
\begin{aligned}
& J_{y} \ddot{\theta}+B_{y} \dot{\theta}+I_{g} \dot{\alpha}=T \\
& J_{z} \ddot{\alpha}+B_{z} \dot{\alpha}-I_{g} \dot{\theta}=0
\end{aligned}
$$

Where

$J_{y}$ moment of inertia about the y-axis

$J_{z}$ moment of inertia about the z-axis

$B_{y}$ damping friction about the $y$-axis

$B_{z}$ damping friction about the z-axis

$I_{g}$ moment of inertia of the gyroscope rotor about its own axis and its velocity.

Taking the Laplace transfer of Equation (1) and Equation (2) yields

$$
\begin{gathered}
J_{y} \theta(s) s^{2}+B_{y} \theta(s) s+I_{g} \alpha(s) s=T(s) \\
J_{z} \alpha(s) s^{2}+B_{z} \alpha(s) s-I_{g} \theta(s) s=0
\end{gathered}
$$

The only actuated axis is the y-axis and the control input in the single-input single-output (SISO) system is the torque applied in the $y$-axis, $T$. The transfer function of the system becomes 


$$
G(s)=\frac{\alpha(s)}{T(s)}=\frac{1}{J_{y} J_{z} s^{3}+\left(B_{z}+B_{y} J_{z}\right) s^{2}+\left(B_{y} B_{z}+I_{g}^{2}\right) s}
$$

The parameters of the system are shown in Table 1 below.

Table 1 System parameter

\begin{tabular}{|c|c|c|c|}
\hline No & Parameter & Symbol & Value \\
\hline 1 & Moment of inertia about the y-axis & $J_{y}$ & $0.00429 \mathrm{Kg} \cdot \mathrm{m}^{2}$ \\
\hline 2 & Moment of inertia about the z-axis & $J_{z}$ & $0.02453 \mathrm{Kg} \cdot \mathrm{m}^{2}$ \\
\hline 3 & damping friction about the y-axis & $B_{y}$ & $0.01584 \mathrm{Nms}$ \\
\hline 4 & damping friction about the z-axis & $B_{z}$ & $0.018756 \mathrm{Nms}$ \\
\hline 5 & $\begin{array}{c}\text { Moment of inertia of the gyroscope rotor } \\
\text { about its own axis and its velocity. }\end{array}$ & $I_{g}$ & $0.00484 \mathrm{Kg} \cdot \frac{\mathrm{m}^{2}}{\mathrm{~s}}$ \\
\hline
\end{tabular}

The transfer function becomes

$$
G(s)=\frac{\alpha(s)}{T(s)}=\frac{9503}{s^{3}+182 s^{2}+3.05 s}
$$

\section{Proposed Controllers Design}

\subsection{Linear Quadratic Integral Controller Design}

LQI computes an optimal state-feedback control law for the tracking loop. Block diagram of a quarter vehicle electromagnetic suspension system with LQI controller is shown in Figure 2 below.

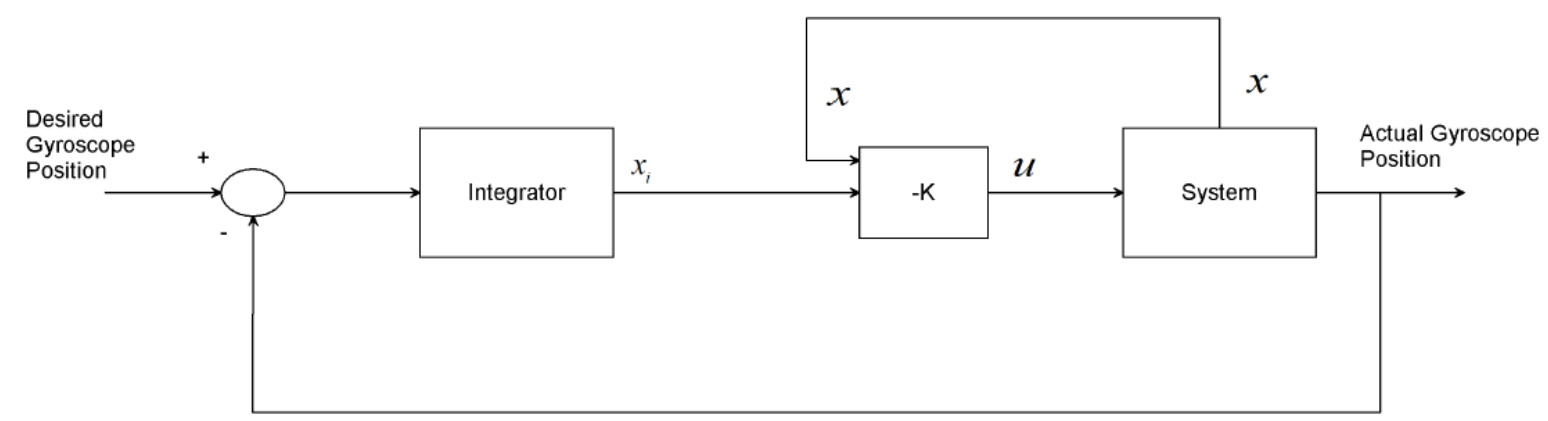

Figure 2 Block diagram of a quarter vehicle electromagnetic suspension system with LQI controller

For a plant sys with the state-space equations

$$
\begin{aligned}
& \dot{x}=A x+B u \\
& y=C x+D u
\end{aligned}
$$


The state-feedback control is of the form

$$
u=-K\left[x, x_{i}\right]
$$

Where $x_{i}$ is the integrator output. This control law ensures that the output $y$ tracks the reference command $r$. For MIMO systems, the number of integrators equals the dimension of the output $y$. LQI calculates the optimal gain matrix $\mathrm{K}$, given a state-space model SYS for the plant and weighting matrices $\mathrm{Q}, \mathrm{R}, \mathrm{N}$.

The value of $\mathrm{Q}, \mathrm{R}$ and $\mathrm{N}$ is chosen as

$$
Q=\left(\begin{array}{llll}
5 & 0 & 0 & 0 \\
0 & 5 & 0 & 0 \\
0 & 0 & 5 & 0 \\
0 & 0 & 0 & 5
\end{array}\right) ; R=10 \text { and } N=\left[\begin{array}{l}
1 \\
0 \\
0 \\
1
\end{array}\right]
$$

The LQI optimal gain matrix becomes

$$
K=\left[\begin{array}{llll}
0.3030 & 5.4075 & 33.7473 & -0.7071
\end{array}\right]
$$

\subsection{Linear Quadratic State Feedback Regulator Control}

Linear quadratic state feedback regulator control is a manipulate scheme that gives the pleasant feasible performance with respect to a few given degree of performance. The overall performance degree is a quadratic feature composed of state vector and manage input. Linear quadratic state feedback regulator is the top of the line principle of pole placement method. Linear quadratic state feedback regulator algorithm defines the gold standard pole place primarily based on two main feature. To find the finest gains, one need to define the most advantageous performance index first of all and then clear up algebraic Riccati equation. Linear quadratic state feedback regulator does now not have any unique strategy to outline the value feature to attain the most suitable gains and the cost function need to be described in iterative manner.

Linear quadratic state feedback regulator is a manipulate scheme that offers the quality feasible overall performance with respect to a few given measure of overall performance. The linear quadratic state feedback regulator design hassle is to design a state comments controller $\mathrm{K}$ such that the index performance $\mathbf{J}$ is minimized. In this method a remarks gain matrix is designed which minimizes the objective feature so as to achieve some compromise between the usage of control attempt, the importance, and the speed of reaction a good way to assure a stable system. Designer pick the correct cost of $\mathrm{Q}, \mathrm{R}$ and $\mathrm{N}$ to discover the perfect benefit matrix $\mathrm{K}$ the usage of MATLAB. The state variable configuration is shown below in Figure 3. 


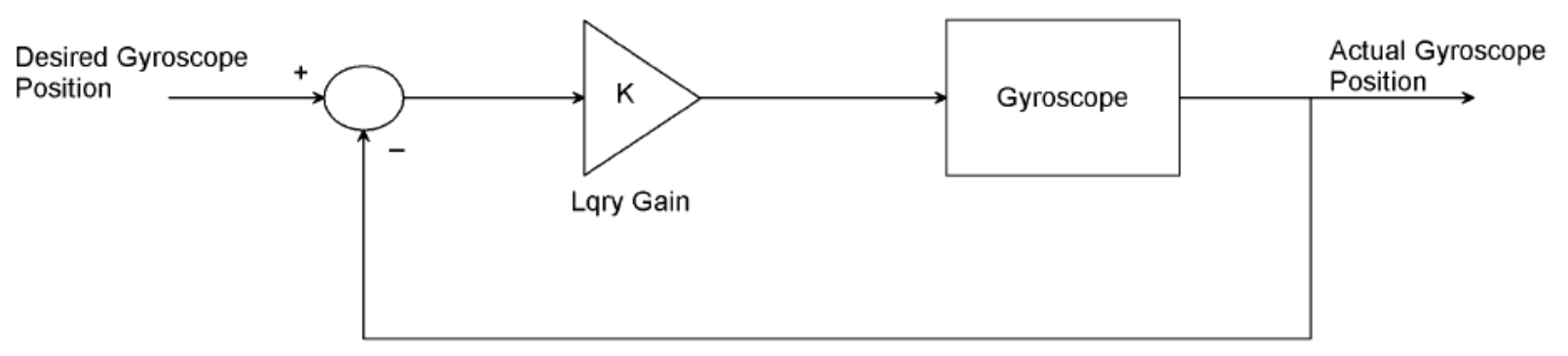

Figure 3 State variable feedback configuration

In this paper, the value of $\mathrm{Q}, \mathrm{R}$ and $\mathrm{N}$ is chosen as

$$
Q=54 \quad R=10 \quad N=1
$$

The value of obtained feedback gain matrix $\mathrm{K}$ of lqry is given by

$$
K=\left(\begin{array}{lll}
0.1190 & 11.2860 & 172.5233
\end{array}\right)
$$

\section{Result and Discussion}

\subsection{Controllability and Observability of the Pendulum}

A system (state space representation) is controllable iff the controllable matrix $C=[\mathrm{B} A B \mathrm{~A} 2 \mathrm{~B} \ldots$. An-1B] has rank $n$ where $n$ is the number of states in the system,

In our system, the controllable matrix $\mathrm{C}=[\mathrm{B} \mathrm{AB} \mathrm{A} 2 \mathrm{~B}]$ has rank 3 which the number of degree of freedom of the system. So, the system is controllable.

A system (state space representation) is Observable if the Observable Matrix D $=$ [C CA CA2... CAn-1] T has a full rank $n$.

In our system, the Observable Matrix $\mathrm{D}=[\mathrm{C} \mathrm{CA} \mathrm{CA2}] \mathrm{T}$ has a full rank of 3 which the number of states of the system. So, the system is Observable.

\subsection{Comparison of the Gyroscope with LQI and LQRY Controllers for Tracking a Desired Angular Position using Step Input Signal}

The comparison simulation of the gyroscope with LQI and LQRY controllers for tracking a desired step change from 0-35-degree angular position is shown in Figure 4 below. 


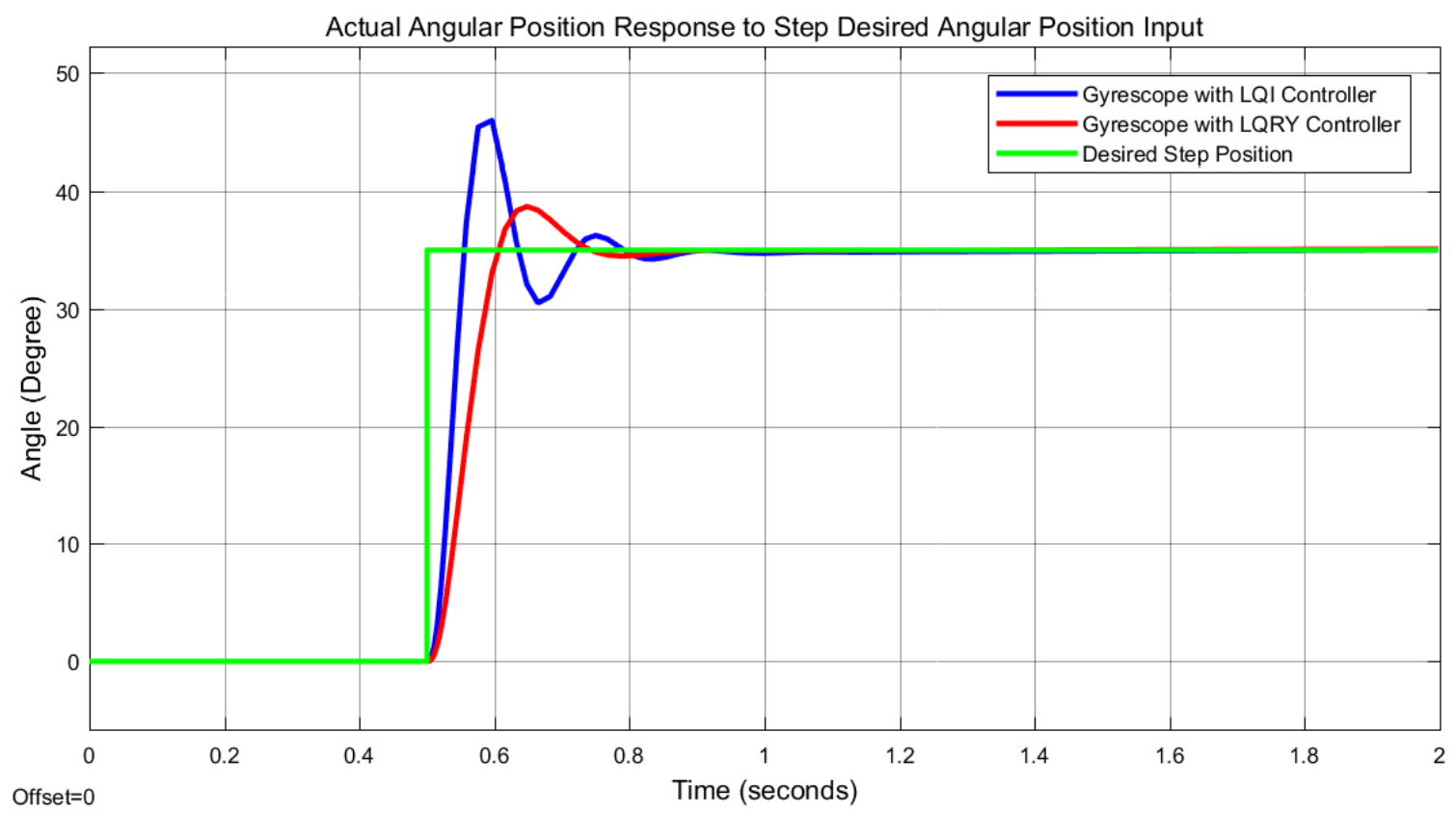

Figure 4 Step response result

The corresponding torque input for the gyroscope with LQI and LQRY controllers is shown in Figure 5 and Figure 6 respectively.

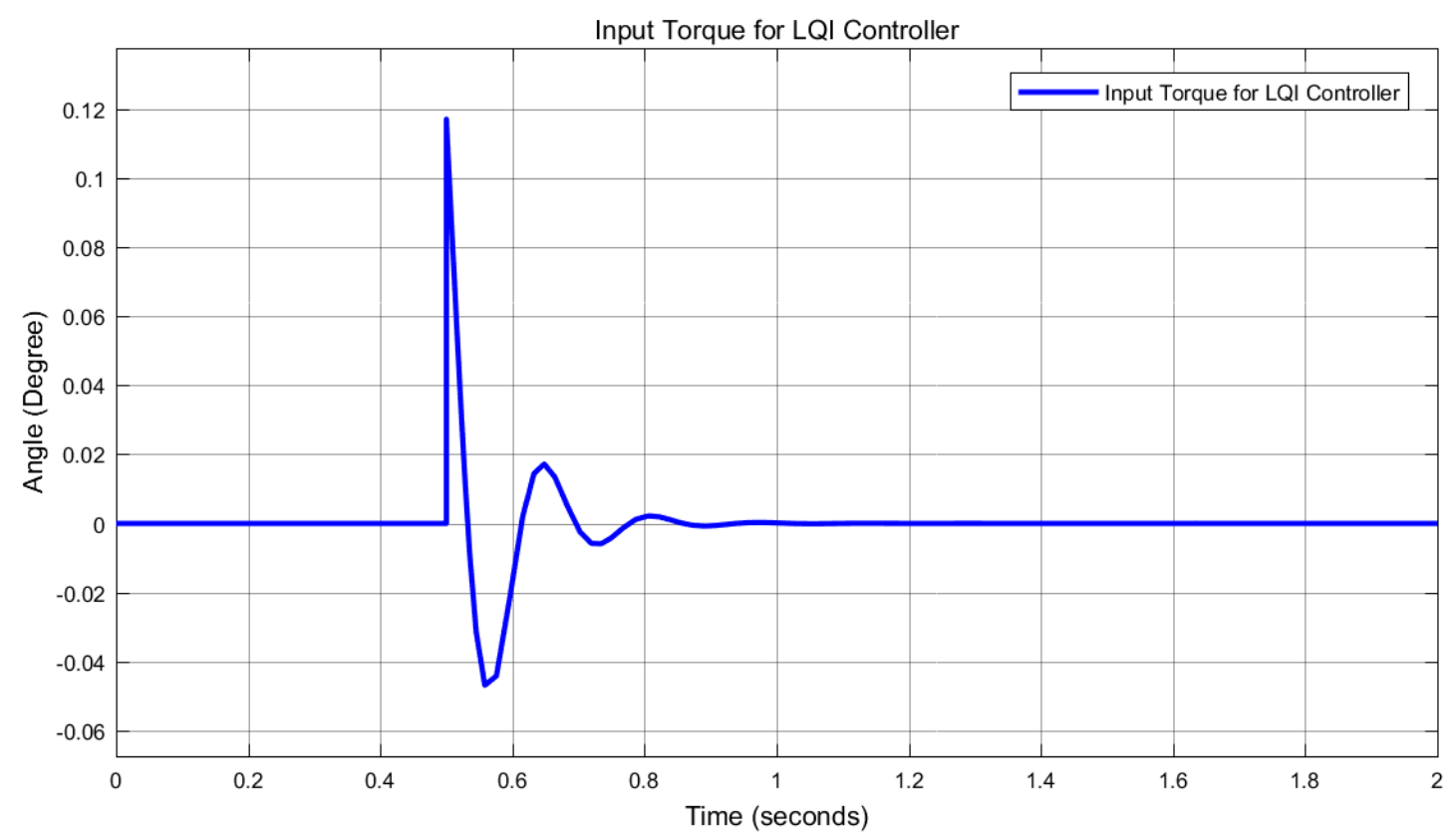

Figure 5 Torque input for the gyroscope with LQI controller 


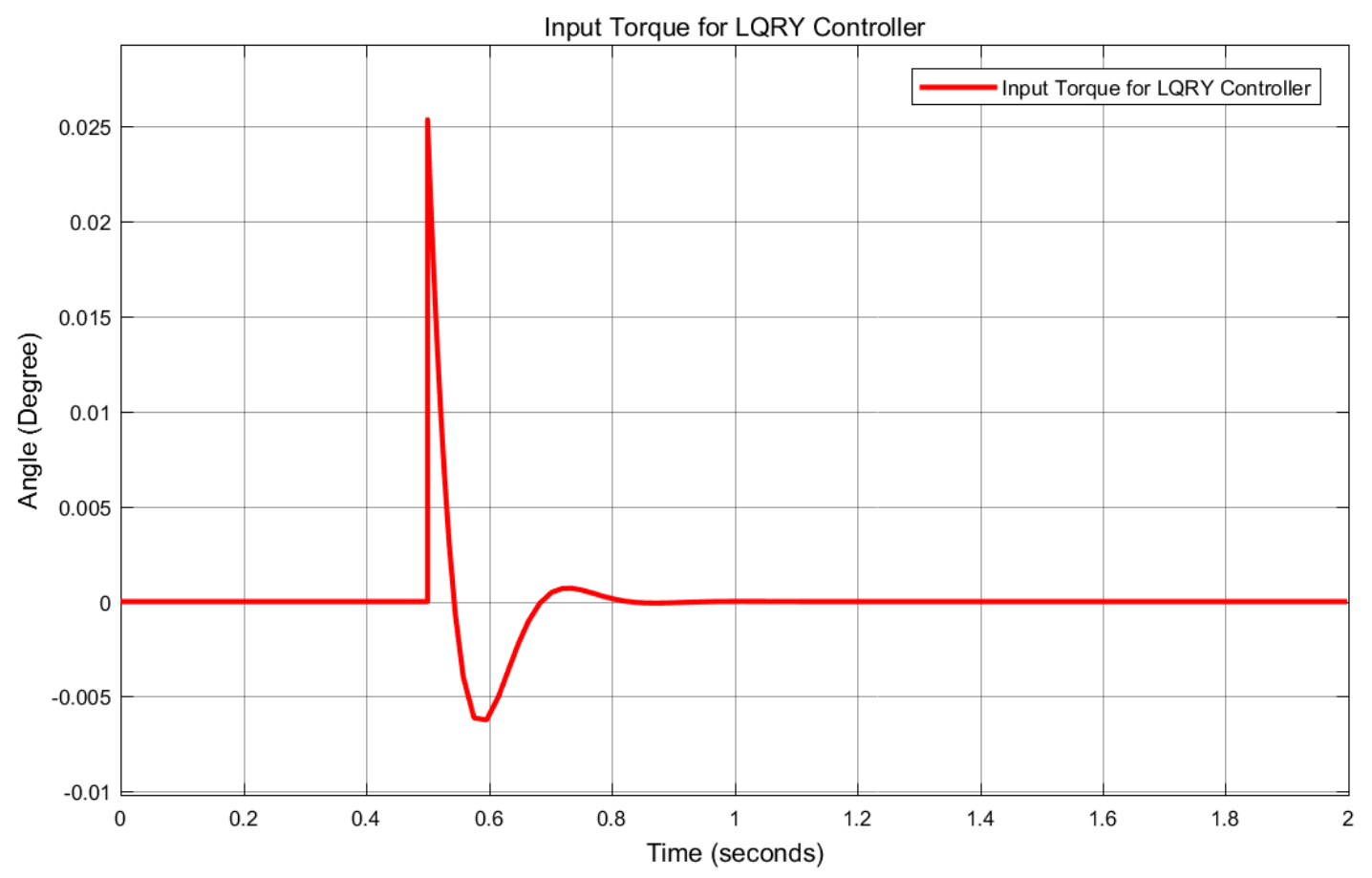

Figure 6 Torque input for the gyroscope with LQRY controller

The data of the rise time, percentage overshoot, settling time and peak value is shown in Table 2.

Table 2 Step response data

\begin{tabular}{|l|l|l|l|}
\hline No & Performance Data & \multicolumn{1}{|c|}{ LQRY controller } & LQI controller \\
\hline 1 & Rise time & $0.56 \mathrm{sec}$ & $0.54 \mathrm{sec}$ \\
\hline 2 & Per. overshoot & $8.57 \%$ & $34.2 \%$ \\
\hline 3 & Settling time & $0.75 \mathrm{sec}$ & $0.88 \mathrm{sec}$ \\
\hline 4 & Peak value & 37 Degree & 47.3 Degree \\
\hline
\end{tabular}

As Table 2 shows that the gyroscope with LQRY controller improves the performance of the system by minimizing the percentage overshoot and settling time.

\subsection{Comparison of the Gyroscope with LQI and LQRY Controllers for Tracking a Desired Angular Position using Random Input Signal}

The comparison simulation of the gyroscope with LQI and LQRY controllers for tracking a desired random change between 3 and 35-degree angular position is shown in Figure 7 below. 


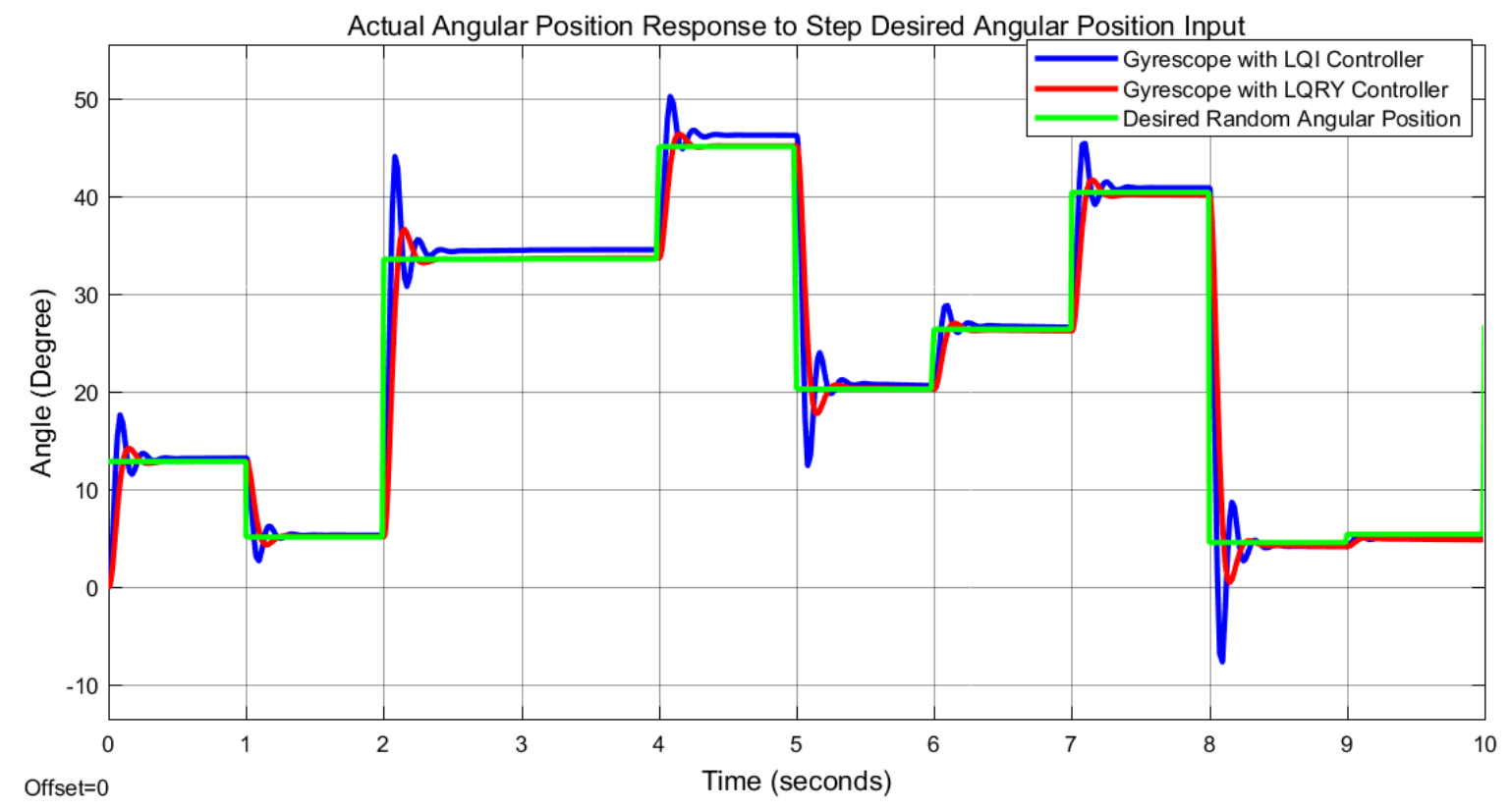

Figure 7 Random response result

The corresponding torque input for the gyroscope with LQI and LQRY controllers is shown in Figure 8 and Figure 9 respectively.

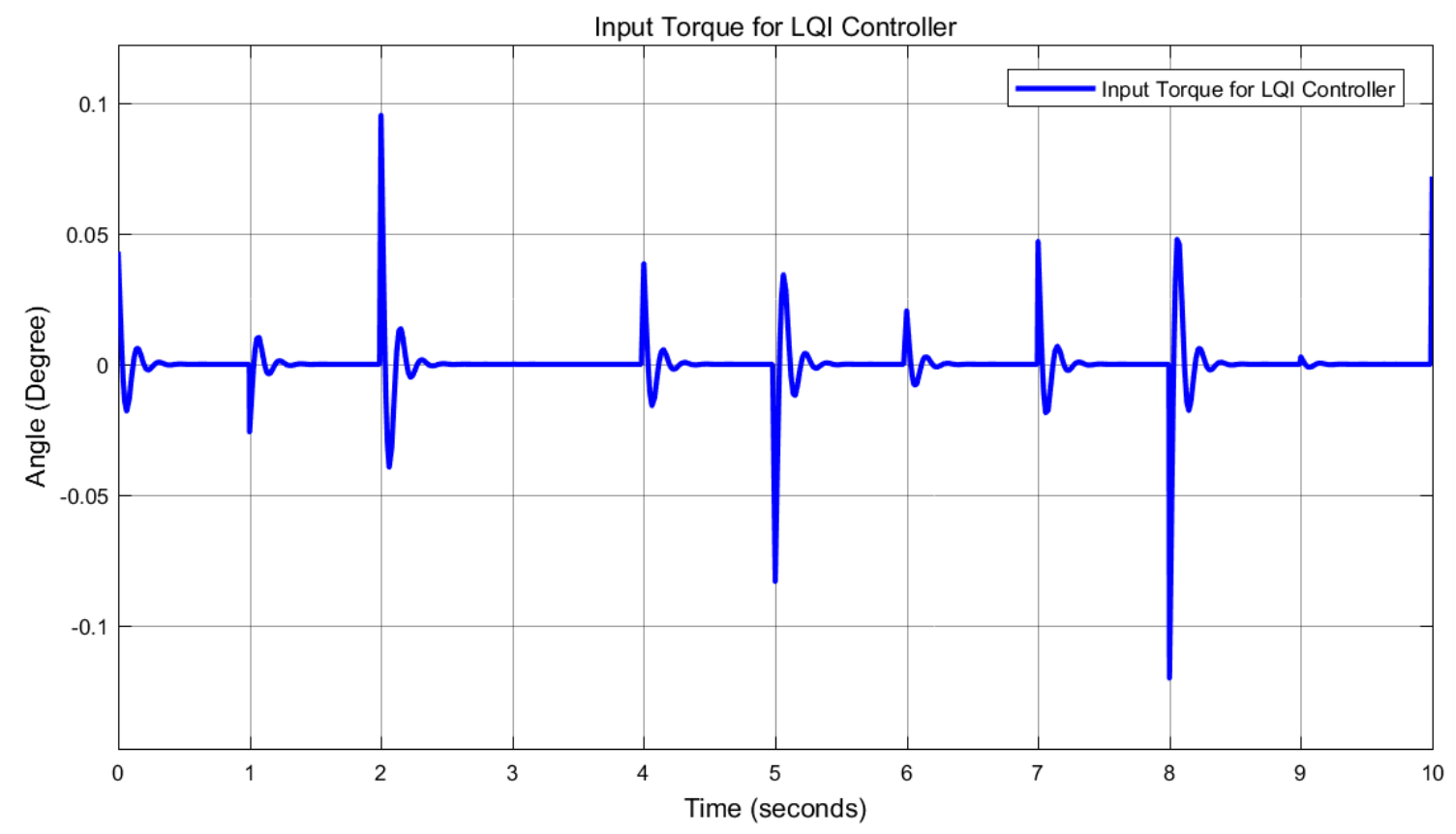

Figure 8 Torque input for the gyroscope with LQI controller 


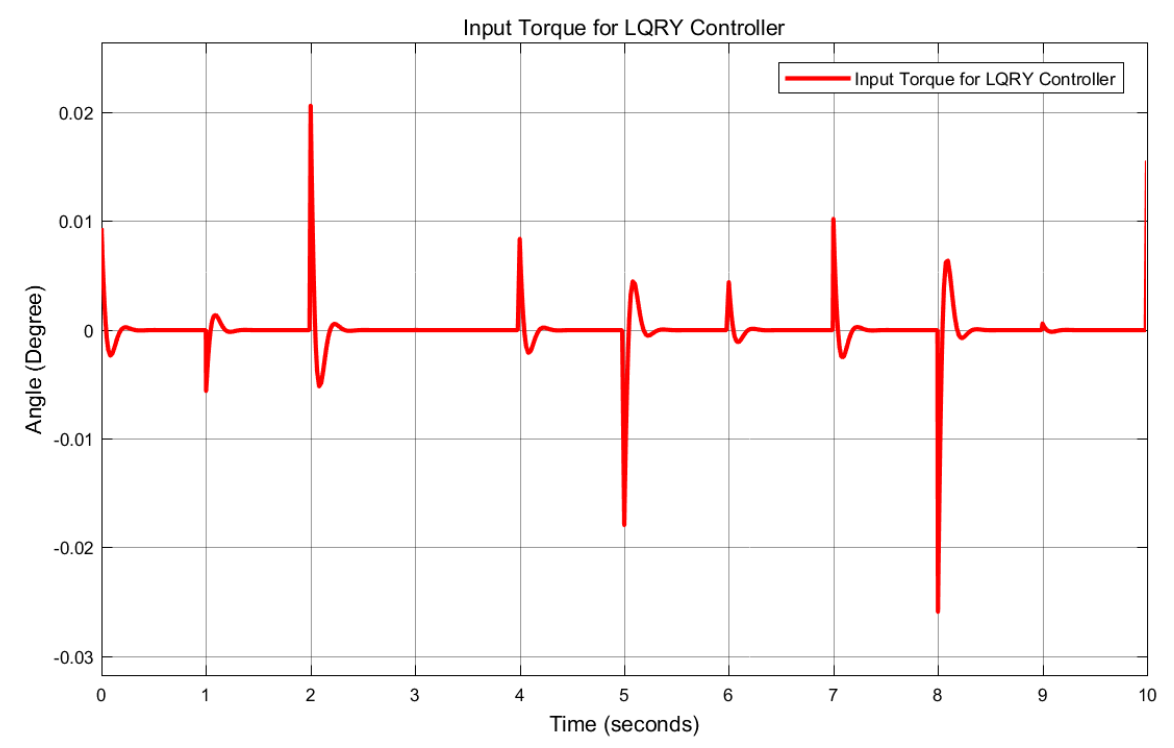

Figure 9 Torque input for the gyroscope with LQRY controller

As we seen from Figure 7, the gyroscope with LQRY controller improves the performance of the system by minimizing the percentage overshoot and settling time.

\section{Conclusion}

This study aims to improve the performance of a 3 DOF gyrscope position control using Linear Quadratic Integral (LQI) and Linear Quadratic State Feedback Regulator (LQRY) controllers. The comparison simulation results of the system with the proposed controllers for tracking a desired step and random angular position shows that in both inputs the gyroscope with LQRY controller improves the performance of the system by minimizing the percentage overshoot and settling time.

\section{Reference}

[1]. Ryspek U. et al. "Inertial Forces Acting on a Gyroscope" Journal of Mechanical Science and Technology, Vol. 32, Issue 1, pp. 101-108, 2018.

[2].P.J.W. Koelewijn et al. "LPV Control of a Gyroscope with Inverted Pendulum Attachment" IFAC-PapersOnline, Vol. 51, Issue 26, pp. 49-54, 2018.

[3]. Mohammed R. et al. "Comparison of Position Control of a Gyroscopic Inverted Pendulum using PID, Fuzzy Logic and Fuzzy PID Controllers” International Journal of Fuzzy Logic and Intelligent Systems, Vol. 18, Issue 2, pp. 103-110, 2018.

[4]. Sinan B. et al. "Composite Adaptive Control of Single Gimbal Control Moment Gyroscope Supported by Active Magnetic Bearings" Journal of Aerospace Engineering, Vol. 30, Issue $1,2017$.

[5]. Talha M. et al. "Design of Fuzzy Tuned PID Controller for Anti Rolling Gyro (ARG) Stabilizer in Ships" International Journal of Fuzzy Logic and Intelligent Systems, Vol. 17, pp. 210-220, 2017.

[6]. Vittorio M. N. Passaro et al. "Gyroscope Technology and Applications: A Review in the Industrial Perspectives” Sensors (Basel), Vol. 17, Issue 10, 2017. 